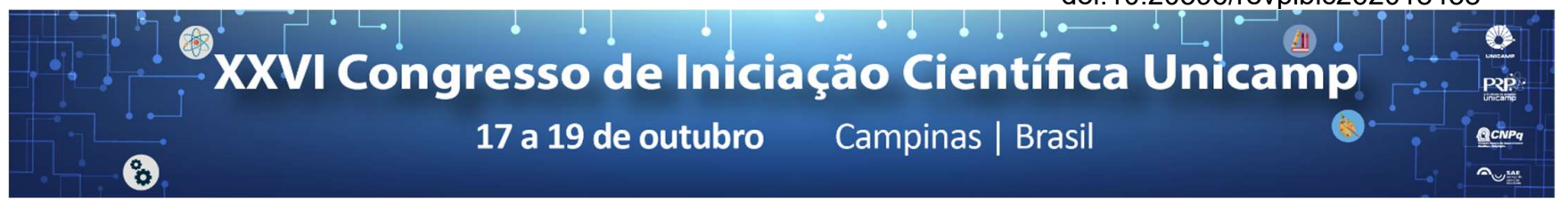

\title{
ANÁLISE DO ÂNGULO GONÍACO DE ACORDO COM SEXO E IDADE UTILIZANDO IMAGENS DE TOMOGRAFIA COMPUTADORIZADA DE FEIXE CÔNICO.
}

\section{Fernando A. Gonçalves*, Carlos Augusto de Souza Lima, Matheus Lima de Oliveira.}

\section{Resumo}

O objetivo com o presente estudo foi analisar o ângulo goníaco para avaliar sexo e idade utilizando imagens de tomografia computadorizada de feixe cônico (TCFC). Duzentas tomografias foram divididas em faixas etárias e sexo, aleatorizadas e dois avaliadores realizaram a medida do ângulo goníaco, utilizando como referência os pontos gnátio e condílio. Não houve diferença significativa para nenhuma das faixas etárias estudadas e a concordância intra e inter avaliador foi excelente. Assim, concluiu-se não ser possível a predição de idade através de exames de TCFC.

\section{Palavras-chave:}

Antropologia Forense, Determinação da Idade pelo Esqueleto, Tomografia Computadorizada de Feixe Cônico.

\section{Introdução}

As estimativas da idade nos esclarecimentos periciais são de considerável importância na identificação de cadáveres, esqueletos (em contextos arqueológicos ou não), acidentes em massa, e nos casos onde não existam os documentos necessários para a comprovação da idade do indivíduo. ${ }^{1-2}$ Para se estimar a idade existem diversas metodologias: pela erupção dos dentes decíduos e permanentes, através da mineralização da coroa e da raiz na dentição permanente, pela erupção do terceiro molar, pelas suturas cranianas e pelas alterações morfológicas e ângulo mandibular. ${ }^{3} \mathrm{~A}$ mandíbula é tido como um dos ossos do corpo humano que mais sofre transformações no seu desenvolvimento podendo ser influenciado pelo estado de oclusão e idade do sujeito. Desta maneira a medida do seu ângulo pode ser útil na avaliação da idade, uma vez que ela sofre variações ao longo da vida. ${ }^{1-3}$

\section{Resultados e Discussão}

As medidas de ângulo mandibular não diferiram entre os sexos com o teste T de Student $(p>0,05)$.

Para comparação, os grupos foram divididos em faixas etárias como na tabela $1 \mathrm{e}$ foi aplicado a análise de variância (ANOVA) para testar as múltiplas comparações. As comparações mostraram diferença $(p \leq 0,05)$ nos grupos, mas não diferiu dentre eles quando avaliadas as faixas etárias para o sexo masculino. As comparações não mostraram diferença estatística significante para as comparações entre as medidas do sexo feminino.

Figura 1. Exemplo da ferramenta e medida do ângulo mandibular.

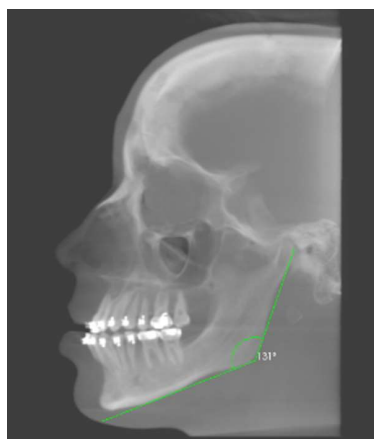

Tabela 1. Média (DP) das medidas do ângulo goníaco por sexo e faixa etária.

\begin{tabular}{|c|c|c|}
\hline Faixa etária & Masculino & Feminino \\
\hline 05 a 10 & $133,9(4,5) \mathrm{A}$ & $122,4(4,1)$ \\
\hline 11 a 15 & $127,1(5,2) \mathrm{A}$ & $124,4(3,5)$ \\
\hline 16 a 20 & $122,6(6,6) \mathrm{A}$ & $123,6(6,5)$ \\
\hline 21 a 25 & $124,5(8,4) \mathrm{A}$ & $124,9(5,5)$ \\
\hline 26 a 30 & $126,0(8,2) \mathrm{A}$ & $126,0(6,9)$ \\
\hline 31 a 35 & $121,4(9,6) \mathrm{A}$ & $125,3(4,6)$ \\
\hline 36 a 40 & $129,0(7,8) \mathrm{A}$ & $125,7(3,0)$ \\
\hline 41 a 45 & $124,2(10,1) A$ & $122,9(4,1)$ \\
\hline 46 a 50 & $124,9(5,7) \mathrm{A}$ & $127,0(6,6)$ \\
\hline 51 a 55 & $119,8(5,3) \mathrm{A}$ & $128,8(3,4)$ \\
\hline 56 a 60 & $120,6(7,6) \mathrm{A}$ & $125,4(2,5)$ \\
\hline
\end{tabular}

\section{Conclusões}

Concluiu-se que as medidas do ângulo goníaco não apresentam relação com as faixas de idade estudadas. Concluiu-se também que o sexo não influenciou as medidas do ângulo goníaco.

\section{Agradecimentos}

À Faculdade de Odontologia de Piracicaba/UNICAMP e ao Conselho Nacional de Desenvolvimento Científico e Tecnológico (CNPq).

\footnotetext{
${ }^{1}$ Schmidt, C.M. Estimativa da Idade e sua Importância Forense [Dissertação de Mestrado]. Piracicaba: Faculdade de Odontologia de Piracicaba, Universidade Estadual de Campinas, 2004.

${ }^{2}$ Birchler, F.A. et al. Dental age assessment on panoramic radiographs in a Swiss population: a validation study of two prediction models. Dentomaxillofac Radiol. 2016;45.

${ }^{3}$ Paiva, F.P.F.; Santiago, A.P.C.S. Estimativa de idade pelo ângulo mandibular utilizando radiografias cefalométricas digitais. Brazilian Journal of Forensic Sciences, Medical Law and Bioethics. 2015;4(4):394-404.
} 